\title{
BMJ Open Quality NO WAIT: new organised well-adapted immediate triage: a lean improvement project
}

Ahmed Elkholi, ${ }^{1}$ Huda Althobiti, ${ }^{1}$ Jamal Al Nofeye,${ }^{2}$ Mohamed Hasan, ${ }^{3}$ Ahmed Ibrahim (i) ${ }^{2}$

To cite: Elkholi A, Althobiti $\mathrm{H}$, Al Nofeye J, et al. NO WAIT: new organised well-adapted immediate triage: a lean improvement project. BMJ Open Quality 2021;10:e001179. doi:10.1136/ bmjoq-2020-001179

Received 24 August 2020 Revised 23 December 2020 Accepted 10 January 2021
Check for updates

(C) Author(s) (or their employer(s)) 2021. Re-use permitted under CC BY-NC. No commercial re-use. See rights and permissions. Published by BMJ.

${ }^{1}$ Emergency Department, Al Hada Armed Forces Hospital, Taif, Saudi Arabia

${ }^{2}$ Continuous Quality Improvement and Patient Safety, Al Hada Armed Forces Hospital, Taif, Saudi Arabia

${ }^{3}$ Center for Health Service and Outcome Research, Northwestern University Feinberg School of Medicine, Chicago, Illinois, USA

Correspondence to Dr Ahmed Ibrahim; ahmedgnouh@gmail.com

\section{ABSTRACT}

Long waiting times in the emergency department (ED) are associated with decreased patient satisfaction and increased morbidity and mortality. Triage may be a contributing factor to prolonged wait times in the ED. At Alhada Armed Forces Hospital (Taif, Saudi Arabia), patients other than level 1 and 2 on the Canadian Triage and Acuity Scale are requested to wait until triage. During peak hours (08:00-22:00), the waiting time prior to triage is prolonged, and several patients leave the ED before triage. In this project, a multidisciplinary team was assembled to revise patient flow from the time of arrival at the ED to the time of triage. Lean methodology was used to identify the redundancies and design a seamless flow process for ED patients. Through reorganising the triage area using minimal additional resources, the project team devised a novel floor plan for the triage area which provided a unique patient flow in the ED. The median patient wait time from arrival to triage was reduced from $27 \mathrm{~min}$ to $4.09 \mathrm{~min}$ and the percentage of patients leaving the ER before triage was reduced to $0 \%$. This project is the first of its kind in Saudi Arabia, as well as in the Gulf region, and provides a radical solution to the problem of patient waiting in the $E D$ during peak hours.

\section{PROBLEM}

Alhada Armed Forces Hospital is a tertiary hospital in the Western region of Saudi Arabia which serves Taif city and receives patients from other military hospitals in the Taif region. More than 90000 patients visited the emergency department (ED) of Alhada Hospital during 2018. Despite an annual 10\% increase in the number of ED visits, there have been no changes to the infrastructure or design of the ED. The ED at Alhada Hospital comprises 40 beds: a resuscitation room (4 beds), 2 isolation rooms ( 2 beds), a short stay and observation room (9 beds), a paediatric room ( 6 beds) and 19 regular ER beds.

Prolonged waiting times and overcrowding in the ED are well-recognised global problems. ${ }^{1}$ Long waiting times before triage carries a negative impact on patient safety, especially for time-sensitive diseases such as acute myocardial infarction and acute surgical conditions. ${ }^{2}$
During the past few years, Alhada Armed Forces Hospital administration has noted patient dissatisfaction with waiting time at the ED during peak hours. Increasingly negative feedbacks and complaints were received by the administration. Moreover, several patients with unstable conditions deteriorated while waiting for triage. In September 2018, the median waiting time from arrival at the ED to triage during peak hours (08:00-22:00) was $27 \mathrm{~min} \quad(\mathrm{IQR}=11 \mathrm{~min}$, range $13-57)$. During September and October 2018, the percentage of patients who left the ED before triage was $6.5 \%$.

This project was established to achieve the goal of providing the required attention to patients visiting the ED with minimal delay by introducing a new design to the triage area that would increase its functional capacity while using its originally assigned space. The aim was to reduce the median waiting time from $27 \mathrm{~min}$ to $4 \mathrm{~min}$, and to reduce the number of patients leaving the ED before triage from $6.5 \%$ to $0 \%-0.5 \%$.

\section{BACKGROUND}

Triage in medicine refers to the process of sorting and prioritising patients. ${ }^{3} 4$ Triage serves as a rapid sorting tool which assists in quick identification of patients in urgent need of medical attention. Despite its obvious benefits, triage has been found to be a potential source of delay. ${ }^{35}$

Several studies have illustrated the serious effect of prolonged waiting and crowding in the ED on patient safety. ${ }^{26-8}$ In 2014, the Joint Commission's Office of Quality and Safety analysed 73 sentinel events that were the result of delays; 48 of those events resulted in patient death. Analysis of 522 sentinel events due to delayed treatment from 2010 to 2014 reported 415 events resulting in patient's death. ${ }^{9}$ Moreover, prolonged wait times are strongly correlated with patient dissatisfaction. $^{1011}$ 
Various approaches are used to improve patients flow through the ED. ${ }^{12}{ }^{13}$ Fast track is one of the triage-related approaches which improves the waiting time and the length of stay at the ED through dividing patients into two separate pathways based on their predicted situation. ${ }^{145}$ Another approach is the inclusion of a physician in the triage team which improves the efficiency of triage and ensures that most patients visiting the ED are seen by a physician. ${ }^{16-18}$ A commonly used approach is the lean thinking methodology. Several studies have established a favourable role for lean thinking in improving patient flow and reducing waiting times in the ED. ${ }^{19} 20$ Reorganising the work space layout according to lean principles has been shown to reduce waiting times, improve work processes, and enhance staff and patient satisfaction. ${ }^{21}$

At Alhada Armed Forces Hospital, ED patients are triaged according to the Canadian Triage and Acuity Scale (CTAS), which uses a combination of criteria (presenting complaint, vital signs and selected modifying factors). ${ }^{22}$ The CTAS score ranges from 1 to 5; CTAS-1 category represents emergency conditions requiring immediate nursing and physician attention to CTAS- 5 category referring to non-urgent conditions, with a recommended initial physician assessment within 2 hours. In practice, patients arriving to Alhada Hospital ED are initially subjected to visual triage by a triage nurse for immediate spotting of cases that require isolation in the respiratory area and CTAS 1-2 category patients (who can be visually identified and directed to the ED without triage). Visual triage is performed by a triage nurse at a designated area at the entrance of the ED known as the visual triage point. The visual triage nurse assesses acute respiratory symptoms in the incoming patients and fills in a specific form for respiratory triage. Patients without respiratory symptoms are directed to the registration desk and then to the CTAS triage room. Patients with respiratory symptoms are taken to respiratory waiting area and will take a different pathway. ${ }^{23}$

After quick registration, patients are requested to wait for their turn in the triage waiting area. The triage area in the ED is composed of two small rooms run by registered nurses and a waiting area. Only two patients are triaged at a time, and other patients are requested to wait for their turn. Patients usually walk between the triage rooms and the waiting area several times until being allocated to a bed. Triage nurses also check the waiting area continuously. During peak hours of weekdays, patient wait times in the ED would have wait for a long time before triage and some patients even left before triage.

\section{MEASUREMENT}

In this project, the assigned team mapped the patient's journey in the ED using a spaghetti diagram to identify the bottlenecks that cause patient queuing and congestion. ED patient data were collected from the health information system (WIPRO) and validated for accuracy, then analysed using the MiniTab Statistical Analysis Software
(V.19.1). The data of 6663 patients who visited the ED during September 2018 were examined to capture peak hours of crowding and patient queuing.

\section{Primary process measurement}

The median time from patient arrival to triage was selected as the primary process measurement. This was defined as the median time from registration of patients to the time of entering their vital sign measurements into the health information system. These data were retrieved retrospectively. The collected data (considered a hospital governance measure) are reported monthly to the Medical Services Directorate of the Ministry of Defense. CTAS 3-5 category patients arriving in the ED during September 2018 during peak hours (08:00-22:00) on weekdays only were included in the study (343 patients). Baseline median waiting time was $27 \mathrm{~min}$ ( $\mathrm{IQR}=11 \mathrm{~min}$ ). This measurement was repeated after the intervention was introduced.

\section{Outcome measurement}

The percentage of patients leaving the ED before triage was chosen as the outcome measurement used to assess the impact of patient waiting. This was calculated by dividing the number of patients who had been registered but their vital signs were not entered into the system by the total number of registered patients. CATS 3-5 category patients arriving in the ED during the months of September and October 2018 during peak hours (08:0022:00) on weekdays were selected. The baseline patient percentage was $6.5 \%$. This measurement was repeated after the intervention was introduced.

\section{DESIGN}

A multidisciplinary team was assembled, comprising the head of the ED, the ED nursing supervisor, a representative from the department of Continuous Quality Improvement and Patient Safety, an Administrative staff member and a staff member from the Maintenance Department. The team received input regarding congestion in the ER from staff members. Team members attended the periodic meetings of the nursing department during which that issue was discussed; ER physicians were invited to these meetings to contribute their experience regarding the causes of congestion in the ER and their ideas on redesigning patient flow.

The lean thinking methodology was selected as the means to fulfil the goal of this study. Lean thinking is a management philosophy whose main principles and practices are based on the Toyota Production System (TPS). TPS defines lean as a management practice based on the philosophy of continuous process improvement by either increasing customer value or reducing nonvalue adding activities (Muda), process variation (Mura) and poor work conditions (Muri) ${ }^{24}$ Lean methodology assigns the term 'waste' to any activity or process that does not add value to the final product or service in the eyes of the customers. According to lean, there are eight types 


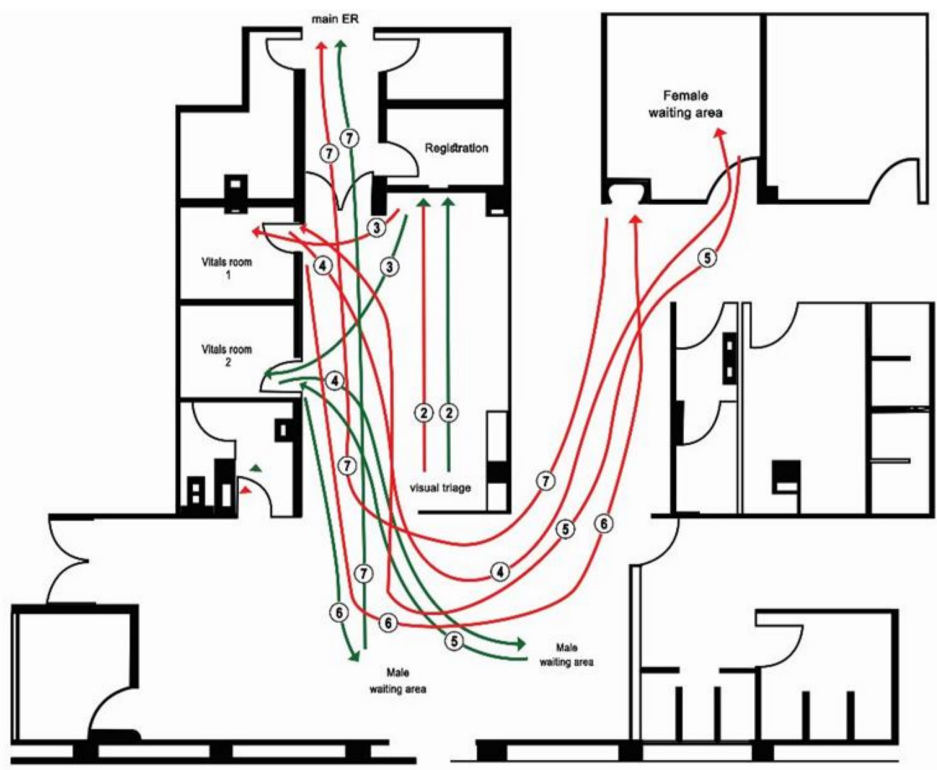

Flow steps:
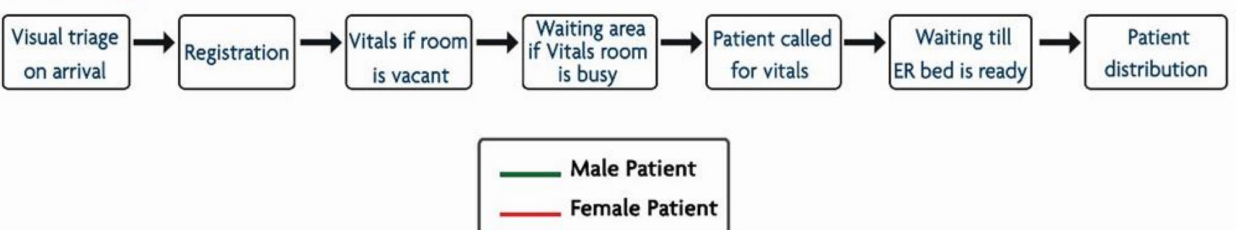

Figure 1 Spaghetti diagram of patient flow in the emergency department prior to NO WAIT intervention.

of waste: defects, overproduction, transportation, waiting inventory, motion, overprocessing and human potential. Practising lean principles eliminates waste through process mapping, analysis and redesign. ${ }^{25}$ All the team members attended a 3-day workshop addressing lean thinking methodology.

The median waiting time in the ED was calculated, which was found to be markedly prolonged. The team thus opted for mapping patient flow in the ED using a spaghetti diagram to identify the reasons for prolonged waiting (figure 1). Spaghetti diagram is a simple mapping tool that observes the distances travelled by patients, staff or products, and helps identify areas where time can be saved through visualising unnecessary movements. ${ }^{26}$

The initial revision of patient flow in the ED revealed inefficient utilisation of the triage area and delayed start of the triage process, leading to congestion in the ED. Several lean types of waste were detected. The main waste was prolonged patient waiting times before triage. Motion waste was demonstrated in the form of multiple trips for both patients and nurses between the waiting area and the triage room. Moreover, overproduction waste was present in the form of the long time spent by nurses to locate the patient to be triaged was noted.

We created a new design for the triage area based on lean principles. 'NO WAIT' was the name given to the new triage model: $N: N$ ew triage design; $O$ : Organised patient flow by removing non-valued movements; WA: Well-Adapted to fit up to 10 patients at once while keeping patient privacy and dignity; IT: Immediate Triage. This model was expected to solve the problems of prolonged patient waiting time and patient congestion in the ED through redesigning the triage area to accommodate the parallel triage of several patients (not just two), without adding further workload to ED nurses; once a patient is connected to the dynamap monitor, the nurse moves on to a second and a third patient, connecting them to their corresponding dynamap monitors, after which she returns to the first patient for recording his vital signs in the patient record sheet, and so forth. This intervention involved redesign of the infrastructure of the ED triage area and its effect was thus expected to be sustainable.

\section{STRATEGY}

Our goal was to improve space utilisation in the triage area, so that more patients could be triaged at the same time and that patients would wait less than 6 min before triage.

Initially, we introduced a new design to the triage area to accommodate the triage of 10 patients, instead of only two, at a time. The new design did not require additional space but depended on reorganising the area already available for triage in the ED and reassigning personnel roles. The floor plan of the registration and waiting areas was redesigned as a single area with a fishbone design: a registration zone (head), 10 triage cubicles (fish bones) and a distribution zone (tail). Thick opaque glass walls were introduced to provide the boundaries for these cubicles (assuring patient privacy), and each cubicle was 

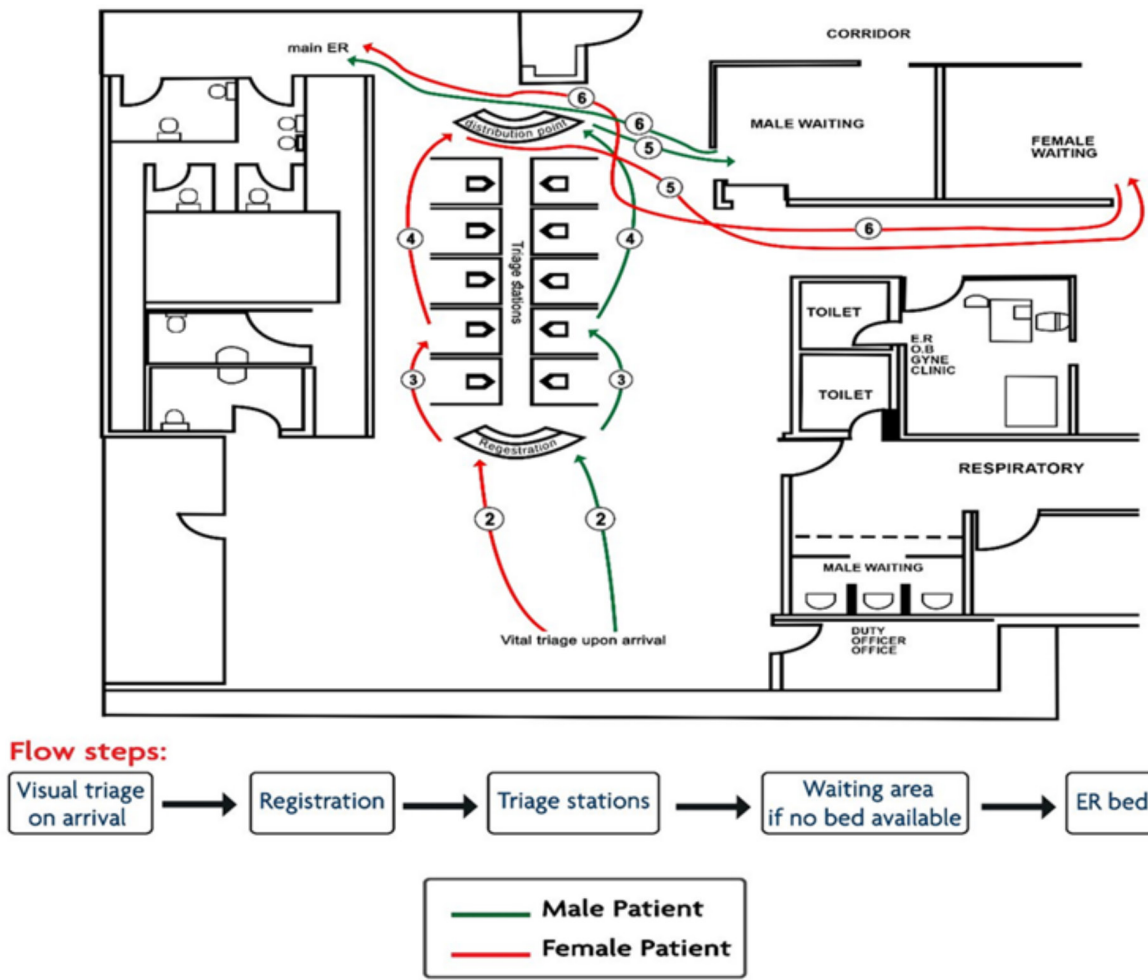

Figure 2 Spaghetti diagram of patient flow in the emergency department after NO WAIT intervention.

equipped with a wall-mounted dynamap. The ED nurse connects a patient to the dynamap monitor in his cubicle, then moves on to a second and a third patient, connecting them to their corresponding dynamap monitors, after which she returns to the first patient for recording his vital signs in the patient record sheet, and so forth. A key change to the triage policy was assigning the registration responsibilities to the ED nurses. Therefore, the administrative staff previously performing patient registration were distributed to other hospital departments, saving the space previously used for registration. The registration, waiting and vital sign recording processes could thus be performed simultaneously. The two rooms which were previously designated as triage rooms were specified for cases that arrive by ambulance on a stretcher and were equipped with wall-mounted dynamaps. Spaghetti diagram retraced patient flow in the ED after introducing the new design (figure 2).

It was noticed during the initial period of implementation that the ED nurses required further orientation to

\section{I-MR Chart of Median Waiting Time}

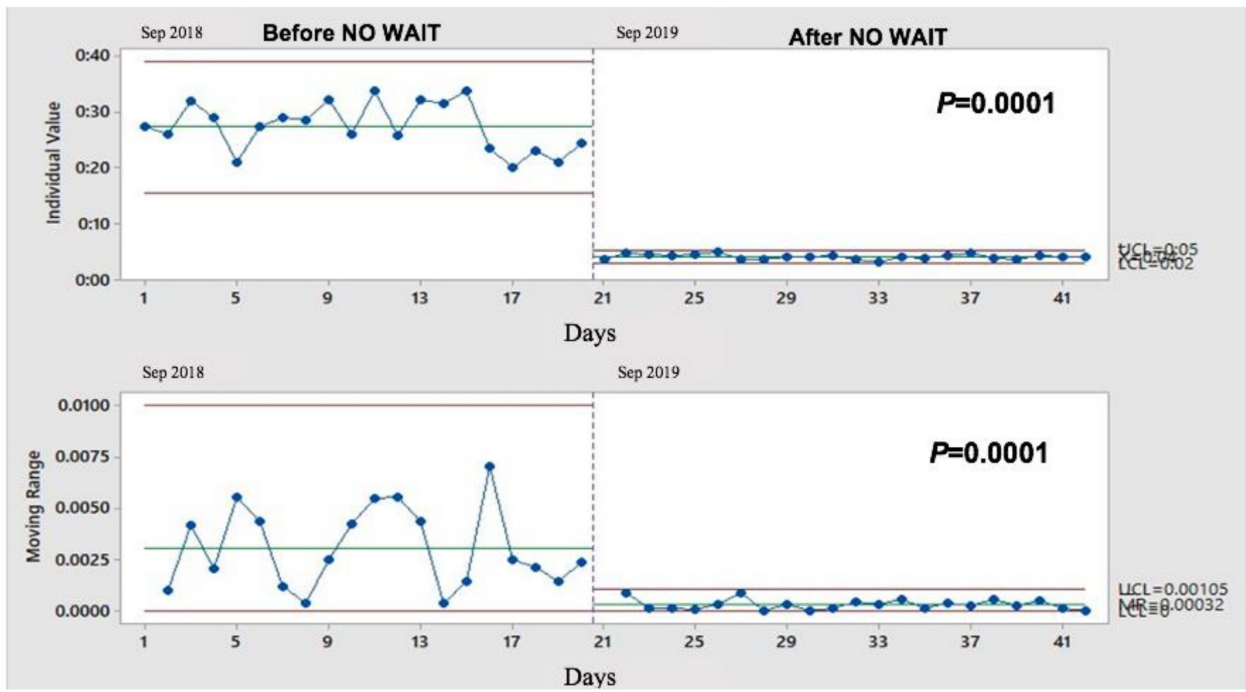

Figure 3 I-MR chart showing median waiting time of patients in the emergency department before and after introducing the NO WAIT intervention. LCL, lower control limit; UCL, upper control limit. 


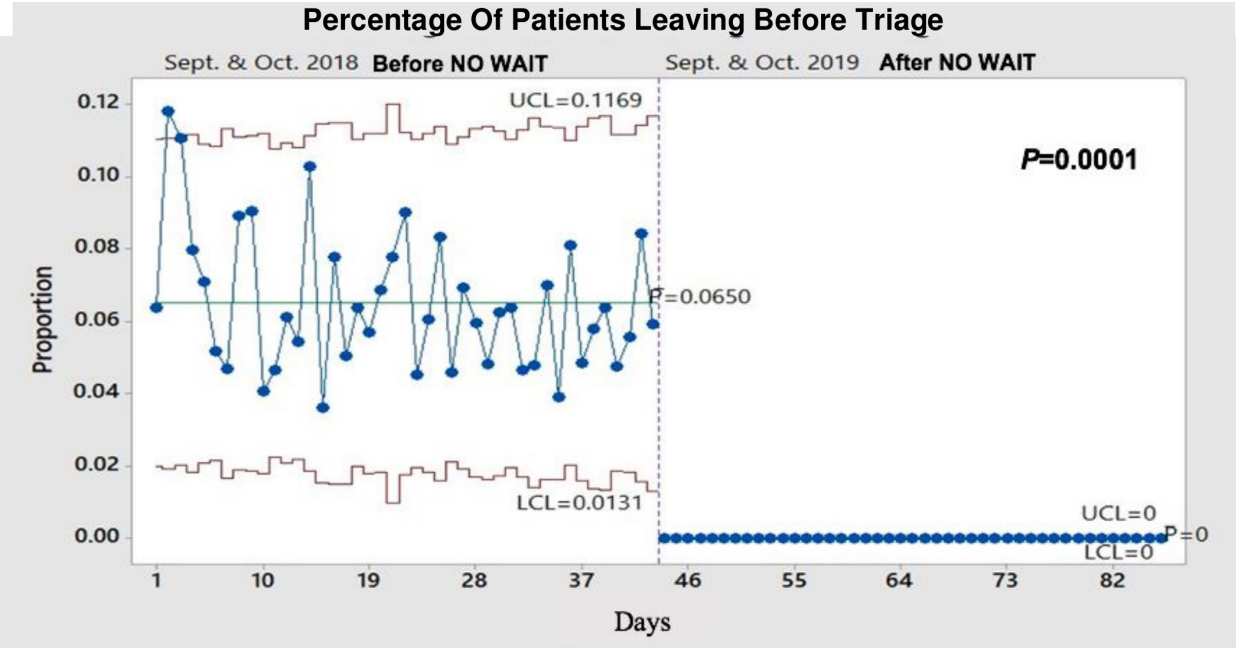

Figure 4 Graph showing percentage of patients leaving the emergency department before triage before and after introducing the NO WAIT intervention. LCL, lower control limit; UCL, upper control limit.

enable them to make full use of the new design. Paramedics were also oriented about the new design and the locations each suitable for incoming patient. Moreover, a few operational issues which emerged during initial days of implementation were tackled, such as the need to provide wheelchairs in some of the cubicles to suit patients coming in on wheelchairs and the necessity of shifting the visual triage point from the registration area to the entrance of the ED. All the changes performed during this cycle had no effect on waiting times.

\section{RESULTS}

\section{Post-measurement}

The median time from patient arrival to triage, chosen as the primary process measurement for this project, was calculated after introducing the triage intervention for CATS 3-5 category patients arriving in the ED during peak hours (08:00-22:00) on weekdays during September 2019 (timing similar to that of pre-measurement to avoid seasonal variation).

The percentage of patients leaving the ED before triage, used as the outcome measurement for this project, was calculated after triage area renovation for CATS 3-5 category patients arriving in the ED during peak hours (08:00-22:00) on weekdays during the months of
September and October 2019 (timing similar to that of pre-measurement to avoid seasonal variation).

Moreover, to determine if the triage intervention led to problems in other parts of the service, we assessed ED staff satisfaction with the intervention and whether the new design improved the experience of nurses or added more to their workload. ED staff (ED physicians, nurses, Emergency Medical Services (EMS) personnel) were requested to fill in a brief survey after the new design was in place. The survey consisted of seven questions with standard 5-point responses (1-strongly disagree to 5-strongly agree). The survey questions were (1) NO WAIT design has improved patient satisfaction in ED, (2) NO WAIT design has solved waiting problem, (3) NO WAIT design has accelerated triage process, (4) NO WAIT design has helped pick urgent cases, (5) NO WAIT design has decreased workload, (6) NO WAIT design has improved communication and (7) NO WAIT design has shortened length of stay.

\section{Results}

This project commenced in July 2019 and the triage intervention was introduced in September 2019. ED patient data were retrieved retrospectively from the

Table 1 Perspective of all emergency department staff on the NO WAIT intervention $(n=164)$

\begin{tabular}{lllllll}
\hline NO wAIT intervention & $\begin{array}{l}\text { Strongly agree } \\
\text { (5) }\end{array}$ & $\begin{array}{l}\text { Agree } \\
\text { (4) }\end{array}$ & $\begin{array}{l}\text { Neutral } \\
\text { (3) }\end{array}$ & $\begin{array}{l}\text { Disagree } \\
\text { (2) }\end{array}$ & $\begin{array}{l}\text { Strongly disagree } \\
\text { (1) }\end{array}$ & $\begin{array}{l}\text { Overall } \\
\text { rating }\end{array}$ \\
\hline Improved patient satisfaction & $65 \%$ & $24 \%$ & $9 \%$ & $0 \%$ & $2 \%$ & 4.50 \\
\hline Solved waiting problem & $61 \%$ & $29 \%$ & $8 \%$ & $0 \%$ & $2 \%$ & 4.48 \\
\hline Accelerated triage process & $60 \%$ & $26 \%$ & $12 \%$ & $1 \%$ & $1 \%$ & 4.43 \\
Helped pick urgent cases & $67 \%$ & $25 \%$ & $6 \%$ & $1 \%$ & $1 \%$ & 4.56 \\
Decreased workload & $56 \%$ & $22 \%$ & $15 \%$ & $3 \%$ & $4 \%$ & 4.21 \\
\hline Improved communication & $57 \%$ & $29 \%$ & $11 \%$ & $1 \%$ & $2 \%$ & 4.39 \\
\hline Shortened length of stay & $61 \%$ & $24 \%$ & $11 \%$ & $2 \%$ & $2 \%$ & 4.39 \\
\hline
\end{tabular}


Table 2 Perspective of emergency department nurses on the NO WAIT intervention $(n=103)$

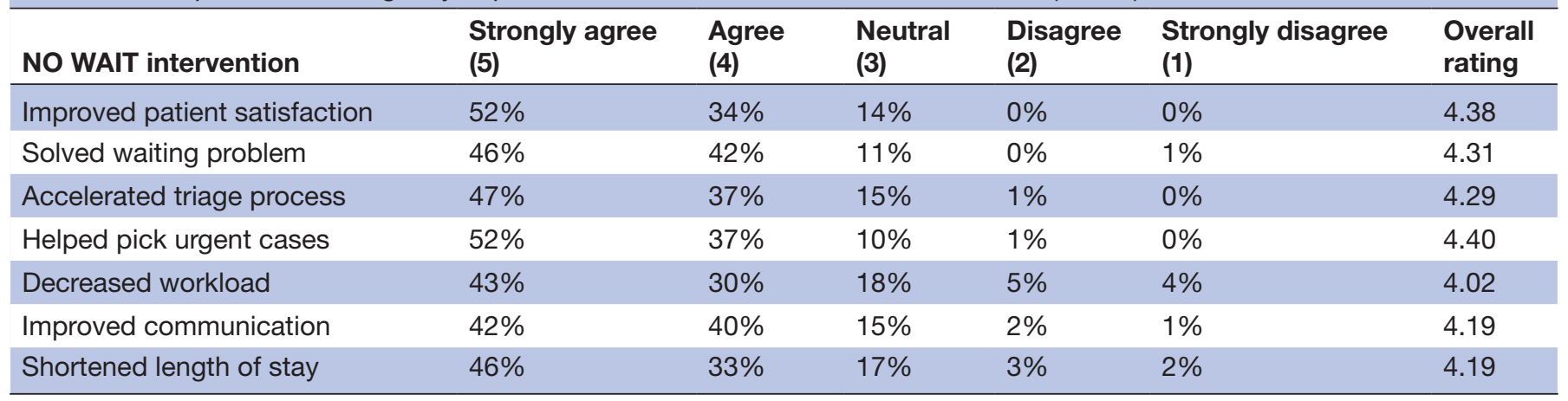

health information system. Post-intervention data were compared with pre-intervention data for the same month(s) of the previous year to avoid seasonal variation.

Our primary process measurement was the median waiting time (in minutes) between patient arrival and triage. Post-intervention data were collected for the month of September 2019 and compared with preintervention data for the month of September 2018. The pre-intervention median waiting time was $27 \mathrm{~min}$ $(\mathrm{IQR}=11 \mathrm{~min})$. After renovation, the median waiting time was dramatically reduced to $4 \mathrm{~min}$ ( $\mathrm{IQR}=1.28 \mathrm{~min}$, $\mathrm{p}=0.0001)$. The individual-moving range (I-MR) control chart showed two measures of improvement: reduction of the variation and shift of the mean (figure 3 ).

The percentage of patients leaving the ED before triage was reduced from $6.5 \%$ during the months of September and October 2018 to $0 \%$ during the same months in 2019 $(\mathrm{p}=0.0001)$. There was no record of any patient leaving the ED before triage since patients were triaged immediately after arrival (figure 4).

Our balancing measurement was the extent of ED staff satisfaction with the intervention. The ED staff includes physicians, nurses and EMS staff members, most of whom participated in the post-intervention survey (table 1). All physicians $(n=35), 103$ out of 104 ED nurses and 26 out of 29 EMS staff responded to the survey. On a 5-point scale, with 5 representing strong agreement and 1 strong disagreement, the ED staff perceived that the NO WAIT design improved patient satisfaction, solved the waiting problem (mean score 4.48), accelerated the triage process, helped pick urgent cases, decreased workload, improved communication and shortened the length of stay (with mean scores of 4.50, 4.48, 4.43, 4.56, 4.21, 4.39 and 4.39 , respectively).

The perspective of ED nurses $(n=104)$ was addressed separately (table 2 ). The mean scores for nurses alone was slightly lower than that of the entire ED staff represented in table 3 , but still reflected their positive perception of the NO WAIT design (NO WAIT design improved patient satisfaction, solved the waiting problem, accelerated the triage process, helped pick urgent cases, decreased workload, improved communication and shortened the length of stay, with mean scores of 4.38, 4.31, 4.29, 4.40, 4.02, 4.19 and 4.19 , respectively). Several of the ED nurses verbally expressed their satisfaction with the new intervention since it saved a lot of time and effort wasted by moving between the waiting area and triage rooms and looking for patient to be triaged. Also, the new design reduced the stress on nurses related to dealing with patients dissatisfied with the long waiting times.

Moreover, comparing Press Ganey survey data for Alhada Armed Forces Hospital in the third quarter of 2019 (before the intervention) and that in the fourth quarter of 2019 (after the intervention) revealed a significant improvement in the overall patient experience as well as in the arrival domain in the ED (table 3 ).

\section{LESSONS AND LIMITATIONS}

The NO WAIT design introduced in this project has several strengths. One obvious strength is its low cost and easy adaptability. We redesigned the ED triage layout by

Table 3 Press Ganey patient experience result (Arrival Domain) at Alhada Armed Forces Hospital emergency department for the third quarter (before NO WAIT intervention) and fourth quarter (after NO WAIT intervention) of 2019

\begin{tabular}{llllr} 
Question & Domain & n & Quarter 3, 2019 & Quarter 4, 2019 \\
\hline Waiting time before staff noticed your arrival & Arrival & 384 & 55.98 & 69.46 \\
\hline Helpfulness of the person who first asked you about your condition & Arrival & 395 & 60.10 & 72.91 \\
Comfort of the waiting area & Arrival & 394 & 44.36 & 56.72 \\
Waiting time before you were brought to the treatment area & Arrival & 397 & 40.35 & 54.91 \\
\hline Waiting time in the treatment area, before you were seen by a doctor & Arrival & 396 & 47.20 & 57.51 \\
\hline
\end{tabular}


creating cubicles made of gypsum board and opaque glass sheets. Such a simple intervention resulted in dramatic improvement in patient flow and patient experience, while preserving patient privacy.

Social distance is a current global necessity to overcome the spread of SARS-CoV-2 infection. ${ }^{27}$ Limiting wait times in the ED is an important strategy to lower the possibility of infection. The NO WAIT design should be considered as an efficient approach to reduce the chance of contracting infections while waiting for triage.

Another notable strength in this design is the ability to detect any case presenting to the ED with timesensitive diagnoses which may deteriorate with delay. Patients with illnesses like acute myocardial infarction, lime ischaemia, testicular torsion and diabetic ketoacidosis could be substantially harmed with waiting ${ }^{2}$ especially during peak hours and should be seen urgently by a physician. In this new design, patients will have their vital signed measured momentarily and thus rapidly allocated.

For patients with non-urgent presentations, visiting the ED and waiting for triage used to be an aggravating situation: the patient was requested to wait despite his suffering and belief that his case required immediate attention. Some ED patients would start fights, others would raise their complaints to the administration and some chose to leave the ED. Nurses also suffered a lot: nurses had to move between the triage rooms and the waiting area several times to call for or find patients and had to deal with ED patients irritated by the long waits. This became part of the past. ED nurses were pleased with the new process as it saved effort and time previously spent in locating patients or comforting them during long waits. Patient experience was quite favourable as ED patients found the new design outstanding.

Nevertheless, we were faced with challenges during the design and application of the intervention. Despite the importance of continuously monitor project performance, this was not possible due to limited resources. We, therefore, opted to a study design that compared findings before and after project implementation. In this extent, we chose the same period to avoid any seasonal variation. Also, the primary process measurement chosen for this project was acquired from the electronic records for the time of ED patient registration and not from the time of arrival at the visual triage point, since those data were difficult to obtain. In addition, the team leader was engaged in long intense meetings with the Maintenance Department to secure buy-in for the renovation to be successful. Moreover, during the 2-month period of renovation, triage was conducted in a temporary location which was not sufficiently prepared for this purpose; this was stressful and less than satisfactory for both ED nurses and patients. Finally, despite of the low cost and limited use of resources, this design might not be reproducible in every hospital since not all hospitals have the necessary funding or ground area.

\section{CONCLUSION}

The project team successfully pinpointed the bottlenecks related to the triage process in the ED using lean thinking methodology and developed an intervention that addressed and solved the problem of congestion and long waiting times. The project has enabled the triage process to be dramatically improved on several levels: patient waiting time, patient safety, patient experience and satisfaction, and staff satisfaction. To assure sustained improvement, the project team continued data collection for estimating the primary process measurement (median waiting time) after the end of the study and nurses were advised to report any cases waiting for more than $6 \mathrm{~min}$ before triage.

Due to the significant success of this project at Alhada Armed Forces Hospital, the NO WAIT design was disseminated to other military hospitals in Saudi Arabia to study, redesign and improve their patient flow in the ED. Further work is underway with other departments in the hospital to apply and use lean methodology to enhance the use of space and resources.

Acknowledgements The project team would like to thank Maj Gen Dr Yasser Babier, Director of the Taif Region Hospital, who believed in the project and allocated the resources necessary to perform this intervention. In addition, thanks are due to Dr Najlaa Al Malki, assistant hospital director for health affairs, for her support and assistance.

Contributors $A E$ is the main author and project team leader-participated in reviewing manuscript. HA, nursing supervisor, was a team member and participated in nursing education. JAN, head of CQI\&PS department and a team member who played an advisory role as process improvement expert-reviewing manuscript. $\mathrm{MH}$ participated in manuscript writing and data analysis. Al, CQI\&PS specialist, was team facilitator and lean specialist—writing manuscript draft.

Funding The authors have not declared a specific grant for this research from any funding agency in the public, commercial or not-for-profit sectors.

Competing interests None declared.

Patient and public involvement Patients and/or the public were not involved in the design, or conduct, or reporting, or dissemination plans of this research.

Patient consent for publication Not required.

Ethics approval Approval of the hospital ethical committee was not required as per hospital policy.

Provenance and peer review Not commissioned; externally peer reviewed.

Data availability statement Data are available upon request.

Open access This is an open access article distributed in accordance with the Creative Commons Attribution Non Commercial (CC BY-NC 4.0) license, which permits others to distribute, remix, adapt, build upon this work non-commercially, and license their derivative works on different terms, provided the original work is properly cited, appropriate credit is given, any changes made indicated, and the use is non-commercial. See: http://creativecommons.org/licenses/by-nc/4.0/.

ORCID iD

Ahmed Ibrahim http://orcid.org/0000-0003-1103-1593

\section{REFERENCES}

1 Lindner G, Woitok BK. Emergency department overcrowding. Wien Klin Wochenschr 2020;22.

2 Derlet RW, Richards JR. Emergency department overcrowding in Florida, New York, and Texas. South Med J 2002;95:846-9.

3 FitzGerald G, Jelinek GA, Scott D, et al. Emergency department triage revisited. Emerg Med J 2010;27:86-92.

4 Christ M, Grossmann F, Winter D. Modern triage in the emergency department. Dtsch Arztebl Int 2010;107:892-8. 
5 Weber EJ, McAlpine I, Grimes B. Mandatory triage does not identify high-acuity patients within recommended time frames. Ann Emerg Med 2011;58:137-42.

6 Pines JM, Pollack CV, Diercks DB, et al. The association between emergency department crowding and adverse cardiovascular outcomes in patients with chest pain. Acad Emerg Med 2009;16:617-25.

7 Bernstein SL, Aronsky D, Duseja R, et al. The effect of emergency department crowding on clinically oriented outcomes. Acad Emerg Med 2009;16:1-10.

8 Trzeciak S, Rivers EP. Emergency department overcrowding in the United States: an emerging threat to patient safety and public health Emerg Med J 2003;20:402-5.

9 Joint Commission. Preventing delays in treatment. Quick Saf, 2015.

10 Bleustein C, Rothschild DB, Valen A, et al. Wait times, patient satisfaction scores, and the perception of care. Am J Manag Care 2014;20:393-400.

11 Abidova A, da Silva PA, Moreira S. Predictors of patient satisfaction and the perceived quality of healthcare in an emergency department in Portugal. West J Emerg Med 2020;21:391-403.

12 Ortíz-Barrios MA, Alfaro-Saíz J-J. Methodological approaches to support process improvement in emergency departments: a systematic review. Int J Environ Res Public Health 2020;17. doi:10.3390/ijerph17082664. [Epub ahead of print: 13 Apr 2020].

13 Oredsson S, Jonsson H, Rognes J, et al. A systematic review of triage-related interventions to improve patient flow in emergency departments. Scand J Trauma Resusc Emerg Med 2011;19:43.

14 leraci S, Digiusto E, Sonntag P, et al. Streaming by case complexity: evaluation of a model for emergency department fast track. Emerg Med Australas 2008;20:241-9.

15 Darrab AA, Fan J, Fernandes CMB, et al. How does fast track affect quality of care in the emergency department? Eur $J$ Emerg Med 2006;13:32-5.
16 Holroyd BR, Bullard MJ, Latoszek K, et al. Impact of a triage liaison physician on emergency department overcrowding and throughput: a randomized controlled trial. Acad Emerg Med 2007;14:702-8.

17 Richardson JR, Braitberg G, Yeoh MJ. Multidisciplinary assessment at triage: a new way forward. Emerg Med Australas 2004;16:41-6.

18 Subash F, Dunn F, McNicholl B, et al. Team triage improves emergency department efficiency. Emerg Med J 2004;21:542-4.

19 Dickson EW, Singh S, Cheung DS, et al. Application of lean manufacturing techniques in the emergency department. J Emerg Med 2009;37:177-82.

20 Falconer SS, Karuppan CM, Kiehne E, et al. ED triage process improvement: timely vital signs for less acute patients. J Emerg Nurs 2018;44:589-97.

21 Reijula J, Tommelein ID. Lean hospitals: a new challenge for facility designers. Intell Build Int 2012;4:126-43.

22 Bullard MJ, Musgrave E, Warren D, et al. Revisions to the Canadian emergency department triage and acuity scale (CTAS) guidelines 2016. CJEM 2017;19:S18-27.

23 Al HISaifi, SKumar G. Use of visual triage in the early identification and isolation of acute respiratory infection cases for the control of hospital outbreak/infection in reference to Middle East respiratory syndrome-corona virus (MERS CoV). Int J Community Med Public Health 2019;9:8-12.

24 Radnor ZJ, Holweg M, Waring J. Lean in healthcare: the unfilled promise? Soc Sci Med 2012;74:364-71.

25 Institute for Health Improvement. Going lean in health care. Innov Ser, 2005: 1-20.

26 NHS. The handbook of quality and service improvement tools. NHS Inst Innov Improv, 2010: 1-320. http://www.miltonkeynesccg.nhs.uk/ resources/uploads/files/NHS III Handbook serviceimprove.pdf

27 Ahmed F, Zviedrite N, Uzicanin A. Effectiveness of workplace social distancing measures in reducing influenza transmission: a systematic review. BMC Public Health 2018;18:518. 